\title{
Pilot Study of Clinician-Patient Collaboration in Glaucoma
}

\author{
Michael Smith (1D) \\ Marco Bresolin' \\ Rose McCabe ${ }^{2}$
}

'Glaucoma Unit, West of England Eye Unit, Exeter, UK; ${ }^{2}$ School of Health Sciences, City, University of London, London, UK
Correspondence: Michael Smith Email Michael.smith26@nhs.net
Purpose: This pilot study was undertaken to examine the feasibility of a larger scale trial examining the effect of interventions to improve patient-clinician collaboration. The primary outcome was the extent of clinician-patient collaboration during glaucoma consultations. The secondary outcomes were the results of the Patient Experience Questionnaire and the patients' opinion of how involved they were in decisions about their care and how keen they would be to increase this involvement.

Methods: This is an observational study of clinician-patient communication involving 9 glaucoma clinicians and 37 patients attending a glaucoma monitoring clinic. Consultations were videotaped and later assessed for the degree of collaboration. Patients completed a validated Patient Experience Questionnaire and a questionnaire designed to collect the patients' opinion of how involved they were in decisions about their care.

Results: The consultations were largely "clinician centred" with clinicians speaking $58 \%$ of the sentences and asking a mean of 8.1 questions compared to the patients 2.6. Glaucoma medications were discussed in $97 \%$ of consultations. When a treatment change was recommended in $53 \%$ of cases different options were discussed. Patients had an overall positive opinion of the consultations. Although $80 \%$ of patients indicated they were happy with how involved they were in decisions about their care $44 \%$ said they would like to be more involved, and $47 \%$ would welcome written information or information sessions on how to be more involved in decisions about their care.

Conclusion: Glaucoma consultations remain "clinician-centred" and, in view of the evidence of the benefits of good clinician-patient collaboration, further studies to examine interventions to improve clinician-patient collaboration may be of benefit to glaucoma patients. These interventions could target both clinicians and patients, and many patients in this study indicated they would like to be more involved in decisions about their care and would welcome support in achieving this.

Keywords: glaucoma, communication, ophthalmology

\section{Introduction}

Traditionally, the doctor-patient relationship was paternalistic with the patient seeking help and the doctor expecting their decisions to be silently complied with. ${ }^{1}$ Over the last 20 years, the increase in available treatments combined with social changes and ease of access to information has led to a more patient-centred approach.

Collaborative decision-making (CDM), also referred to as shared decisionmaking (SDM), is the process of information giving and engagement in which health professionals and patients work together to understand clinical issues and 
determine the best course of action. ${ }^{2}$ This approach requires good communication skills and a different approach to medical encounters than the traditional model.

CDM has been identified as an important part of the United Kingdom National Health Service (NHS) Right Care programme and is part of the NHS ambition of a service that encourages "no decision about me, without me". ${ }^{3}$ In addition to the rights of patients to be involved in decisions about their care, CDM may reduce the overuse of unproven treatments, improve the use of proven treatments, reduce healthcare variations and, by encouraging patient ownership of their own healthcare, reduce health costs. $^{4}$

There is an emerging evidence base on the benefits of CDM, but many areas of medicine have been slow to adopt this method of communication and many barriers to widespread implementation have been identified. ${ }^{4-7}$

Glaucoma is well suited to a collaborative approach to decision-making for several reasons. It is a chronic incurable condition which only tends to affect day-to-day visual function in the advanced stages, and although it tends to progress over time, the therapeutic aim is to prevent the disease from progressing to the level where it affects the quality of life. As glaucoma progresses at different rates in different patients, management is an ever-changing balance between the projected benefits of treatment against the side effects and inconvenience of treatment. As the exact position of this balance is dependent on the individual patient's attitude to risk and the perception of the downsides of treatment, the decisions that need to be made are an example of what is described as "preference sensitive" decisions, which are considered ideal candidates for $\mathrm{CDM}^{8}$

CDM offers potential benefits to glaucoma patients both because of the nature of decision-making in glaucoma management and better treatment adherence when there is a more collaborative clinician-patient relationship. Research into CDM in ophthalmology is, however, very limited, and the small number of studies looking at this area in glaucoma has suggested that there is room for improvement. $^{9-11}$

There is evidence from other areas of medicine that patient-clinician collaboration can be improved using interventions targeted at both patients and clinicians. ${ }^{12}$ We are keen to test such interventions in glaucoma but with such a limited evidence base in ophthalmology with which to justify funding and plan study protocols, we decided to undertake a pilot study to determine the feasibility of such a study.

This pilot study examined the extent to which glaucoma consultations meet the principles of collaborative clinician-patient interaction and shared decision-making in video-recorded out-patient consultations. We also collected the patients' perspective of the consultation and explored their willingness to be more involved in decisions about their care. In fitting with current glaucoma care delivery in the UK, this study involved both ophthalmologists and non-medical glaucoma practitioners.

\section{Methods}

This study was approved by our local research ethics committee and by the UK Health Research Authority (IRAS Reference 253400). The study took place on 13 separate days in the Glaucoma Unit at the West of England Eye Unit, Exeter, UK between February and October 2018, the days decided by the availability of the researchers.

\section{Size and Scope of Study}

As a pilot, this study had limited funding and therefore the number of days on which the study took part, and the number of staff and patients who participated, was pragmatic and based on the availability of the researchers. Similarly, the procedures for analysis of the consultations and collection of questionnaire data were based on the available resources.

\section{Recruitment}

All clinical staff in the unit (excluding the researchers) received an information sheet on the study and an invitation to participate. The information sheet explained the study processes and that the study was looking at clinician-patient communication but did not detail the criteria on which clinician-patient interaction would be measured. Those staff members who agreed provided written informed consent. Patient inclusion criteria were individuals over 18-years old attending the glaucoma monitoring clinics with a prior diagnosis of glaucoma, glaucoma suspect or ocular hypertension. Patients agreeing to take part also provided written informed consent. Patients unable or unwilling to consent were excluded.

\section{Procedures}

Study participants had a consultation with a glaucoma clinician and monitoring tests as required by the glaucoma 
technicians as per standard care. The consultation with the clinician was recorded using a GoPro Hero5 camera (GoPro Inc, USA) which records both video and sound. Following the consultation, the patient completed two questionnaires. The first was intended to collect the patients' experience of the consultation which had just been completed, and used the Patient Experience Questionnaire (PEQ), as described by Steine et al, which is a validated measure of the patient experience. ${ }^{13}$ The second questionnaire was designed for this study and recorded the patients' opinion of how involved they were in decisions about their care and how keen they would be to increase this involvement (Appendix 1). The participants were instructed to answer the first questionnaire based on the consultation they had just completed and the second questionnaire based on their overall experience as a glaucoma patient.

\section{Assessment of Collaborative Nature of Consultation}

There are several described methods of assessing consultations in order to determine the extent of a collaborative approach between clinician and patient and the degree of CDM. ${ }^{12,14}$ Although many are specific to one study, there are several that have been used across specialities with some success. These methods have largely been developed to examine situations where a patient needs to make a major treatment decision, such as whether to proceed with surgery. The nature of glaucoma, however, means that major treatment decisions are not required at most consultations, and therefore we felt these methods of assessment were not likely to be useful in this study. We, therefore, set the criteria for assessment based on the previous studies in this subject in glauc ${ }^{9-11}$

We recorded the following information:-

(i) Number of sentences spoken by clinician/patient/ relatives

(ii) Number of questions asked by clinician/patient/ relative

(iii) Open versus closed questions by clinician

(iv) Are medications discussed - what drops are they using, when do they use them, overall adherence, side effects?

(v) If treatment change recommended, is patient given options (including option of no change)?

(vi) Is patient asked if they are happy with/involved in decision about timing of next appointment? (vii) Towards the end of consultation is patient asked if they have any questions?

\section{Outcomes}

The primary outcome of this study was the extent of clinician-patient collaboration during glaucoma consultations. The secondary outcomes were the results of the Patient Experience Questionnaire and the patients' opinion of how involved they were in decisions about their care and how keen they would be to increase this involvement. As a pilot study, we also examined whether the study procedures would be feasible for a larger scale trial examining the effect of interventions to improve patient-clinician collaboration.

\section{Analysis}

The recordings of the consultations were reviewed and assessed for clinician-patient collaboration using the criteria above by two (MS, MB) researchers. The first five consultations were reviewed jointly to ensure a consistent approach with the remainder reviewed independently. Excluding the first five consultations, we calculated inter-rater reliability for the "yes-no" questions using Cohen's Kappa values, interpreting the results according to Landis and Koch guidance. ${ }^{15}$

The data produced by an analysis of the consultations using the criteria above and the patient questionnaire data were recorded and analysed using Microsoft Excel.

\section{Patient Involvement in Study Design}

In preparing this study, we surveyed a small number of patients with established glaucoma attending our unit. This was intended to determine whether patients felt communication between clinician and patient was important in glaucoma and whether they would find the study procedures acceptable.

Seventeen patients participated in the survey and the results suggested that patients with glaucoma agreed that this is an important area for research and the majority would consider taking part in a study in this area. The results also suggested that patients would consent to having their consultations videotaped for this study, with the additional time spent in the clinic likely to be the main barrier to patients agreeing to take part.

\section{Results}

\section{Participants}

Eleven glaucoma clinicians were invited to take part in the study and 9 (82\%) agreed. Four were male and five female. Five were ophthalmologists and four glaucoma practitioners. 
The ophthalmologists were of all grades and the remaining practitioners were from varying primary qualifications such as orthoptics, optometry and nursing. The mean number of consultations per clinician was 4.1 (median 4, range 2-5).

Eighty-one patients were invited to take part in the study and 37 (45.7\%) agreed: their characteristics are summarised in Table 1. Of the 44 who decline participation, $75 \%$ declined to give a reason. Of those who did give a reason the extra time in clinic required was the main consideration $(16 \%)$.

\section{Consultations}

For each participant, the mean of the two observers' answers was calculated and then used for further analysis. For the yes-no answers, the Cohens Kappa value varied ranged from 0.41 to 0.74 , indicating moderate to substantial agreement between the 2 observers.

Consultations lasted a mean of 17.3 (SD 7.2, median 16.4) minutes. During the consultations, the mean number of sentences spoken (this excluded introductions, small

Table I Characteristics of Glaucoma Patients

\begin{tabular}{|c|c|}
\hline Parameter & Value \\
\hline \multicolumn{2}{|l|}{ Sex, n (\%) } \\
\hline Male & $18(48.6 \%)$ \\
\hline Female & $19(5 \mathrm{I} .4 \%)$ \\
\hline \multicolumn{2}{|l|}{ Age (years) } \\
\hline Mean \pm SD (median) & $70.8 \pm 8.6(72)$ \\
\hline Range & $35-43$ \\
\hline \multicolumn{2}{|l|}{ Diagnosis, n (\%) } \\
\hline Glaucoma (all types) & $31(83.8 \%)$ \\
\hline Ocular Hypertension & $4(10.8 \%)$ \\
\hline Glaucoma Suspect & $2(5.4 \%)$ \\
\hline \multicolumn{2}{|l|}{ Years since diagnosis (years) } \\
\hline Mean \pm SD (median) & $10.9 \pm 8.5(9)$ \\
\hline Range & $1-40$ \\
\hline \multicolumn{2}{|l|}{ Number of glaucoma drops } \\
\hline Mean $\pm S D$ (median) & $2.1 \pm I . I(2)$ \\
\hline Range & $2-4$ \\
\hline \multicolumn{2}{|l|}{ Previous glaucoma interventions, $\mathrm{n}(\%)$} \\
\hline Laser & $9(24.3 \%)$ \\
\hline Surgery & $13(35 \%)$ \\
\hline No previous laser or surgery & I 8 (48.6\%) \\
\hline \multicolumn{2}{|l|}{ Visual field defect (mean deviation) } \\
\hline Mean \pm SD (median) & $-5.43 \pm 6.16(-3.20)$ \\
\hline Range & -24.47 to 1.44 \\
\hline
\end{tabular}

talk about weather, etc.) by the clinician was 29.2 $(58.6 \%)$ and by the patient $20.6(39.9 \%)$. Relatives or companions only spoke in $4(10.8 \%)$ of the consultations. In $89 \%$ of consultations, the clinician spoke more sentences than the patient and companion combined.

The clinician asked a mean of 8.1 (SD 3.9, median 7.5) questions, with $55 \%$ being closed questions. A mean of 2.6 (SD 2.4, median 2) questions were asked by the patient about their glaucoma or treatment. In 34/37 (92\%) of cases, the clinician asked more questions than the patient.

We explored whether the patient was asked about their glaucoma medications. Four patients were not using any glaucoma medications. Of the remaining 33 cases, in 32 (97\%) of consultations, there was some discussion about medications with $92 \%$ asked what medications they were using, $74 \%$ about the timing of treatment and $36 \%$ about side effects. In $73 \%$ of consultations, there was discussion about adherence to treatment.

During 17 consultations (46\%) a treatment change was recommended.

In 9 of these 17 (53\%), different options were discussed, and in 4 cases (32\%), this included the option of no change to treatment.

Towards the end of the consultation in $26 \%$ of consultations. the patient was asked whether they agreed with the plan for the timing of the next appointment. In the latter part of the consultations, $35 \%$ of patients were asked if they had any questions.

\section{Questionnaires}

Questionnaire data were available for 36 participants. Figures 1-4 summarise the responses to the standardised PEQ, which was used to capture the participants' experiences of the consultations.

Figures 1-4 indicate patients felt the consultation would have a positive outcome and communication was good with no significant barriers to communication.

Figure 5 summarises the responses to the glaucomaspecific questionnaire on participants' opinion of how involved they were in decisions about their care and how keen they would be to increase this involvement.

In Figure 5 the responses to the first statement indicate patients are happy with how involved they are in decisions about their care. Of the 36 responses, $29(80 \%)$ stated they "agree" or "agree completely" with the statement "I feel happy with how involved I am in decisions about my care", with only 3 (8\%) stating they "disagree" or "disagree completely". The responses to question 2 were more balanced with 16 (44\%) 


\section{Patient Experience Questionnaire questions 1-4: Outcome of this specific visit}

Do you know what to do to reduce your health problems? Or prevent problems?
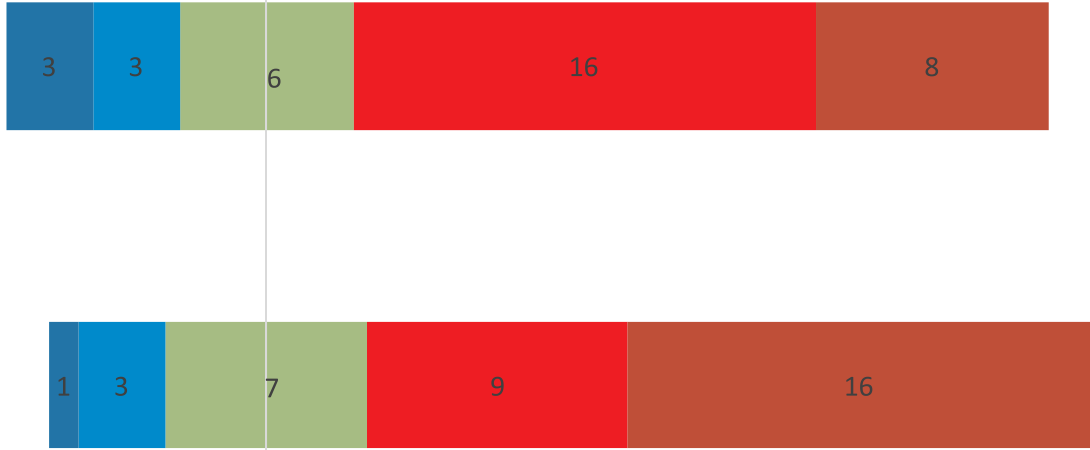

Do you know what to expect from now on?

Will you be able to handle your health problems differently?
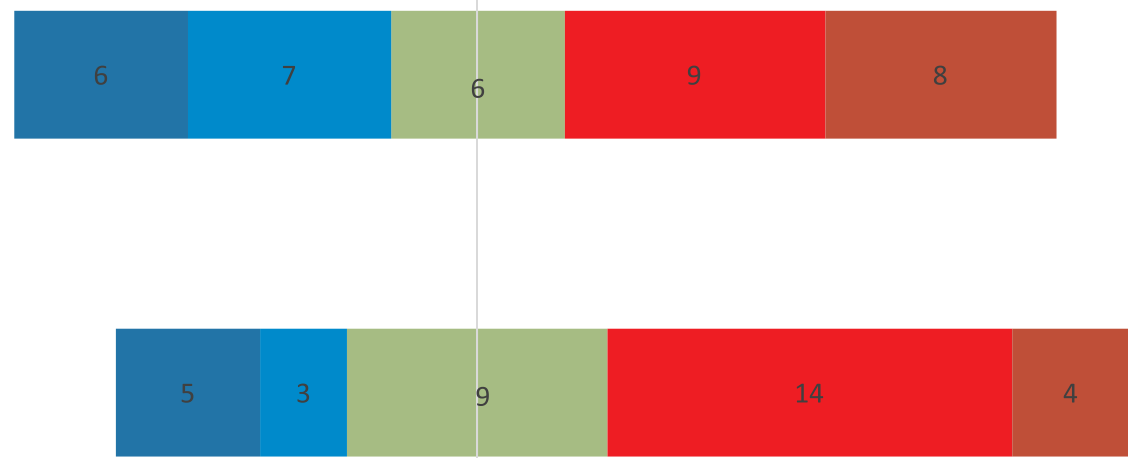
problems?

$\square$ Nomore $\quad$ Not much $\quad$ A bit more $\quad$ Some more $\quad$ Much more

Figure I Results of Patient Experience Questionnaire questions I to 4. Response collected on a 5-point Likert Scale with each question answered by one of the following "no more", "not much", "a bit more", "some more" or "much more". Vertical line indicates most neutral answer. Numbers on boxes indicates number of responses in this category. Adapted from Steine S, Finset A, Laerum E. A new, brief questionnaire (PEQ) developed in primary care for measuring patients' experience of health interaction, emotion and consultation outcome. Fam Pract. 200I;18(4):410-4I7, by permission of Oxford University Press. ${ }^{13}$

stating they "agree" or "agree completely" and 12 (33\%) indicating they "disagree" or "disagree completely" with the statement "I feel I would like to be more involved in decisions about my care". This suggests that although many patients would like to be more involved, others would not. The responses to Questions 3 and 4 are consistent with this, with 17 (47\%) stating they "agree" or "agree completely" with the statements exploring whether they would like to receive written information or attend information sessions on how to be more involved in decisions about their care.

\section{Ophthalmologists and Glaucoma Practitioners}

We compared the results of the video gradings and questionnaires between ophthalmologists and glaucoma practitioners. The ophthalmologists had a longer mean consultation time than the practitioners (19.5 vs $14.5 \mathrm{~min}$ utes) which may indicate a more complicated case mix. The results between the two groups were almost identical for a number of sentences spoken by the clinician $(29.2$ ophthalmologists, 29.3 practitioners), questions asked by the clinician $(8.0,8.3)$ and any discussion about medications $(85.7 \%, 87.5 \%)$. However, in cases where a treatment change was recommended, practitioners discussed different options in more cases $(83.3 \%$ practitioners, $46.4 \%$ ophthalmologists), and in a higher proportion, this included the option of the patient deciding on no change $(50 \%, 28.6 \%)$. Practitioners were also more likely to discuss the timing of the next appointment with the patient $(37.5 \%, 16.7 \%)$ and, towards the end of the consultation, ask if the patient had any questions $(46.9 \%$, $26.2 \%$ ). The patient perception of the consultation, as 


\section{Patient Experience Questionnaire questions 5-8: Communication experiences}

I felt reassured
We had a good talk
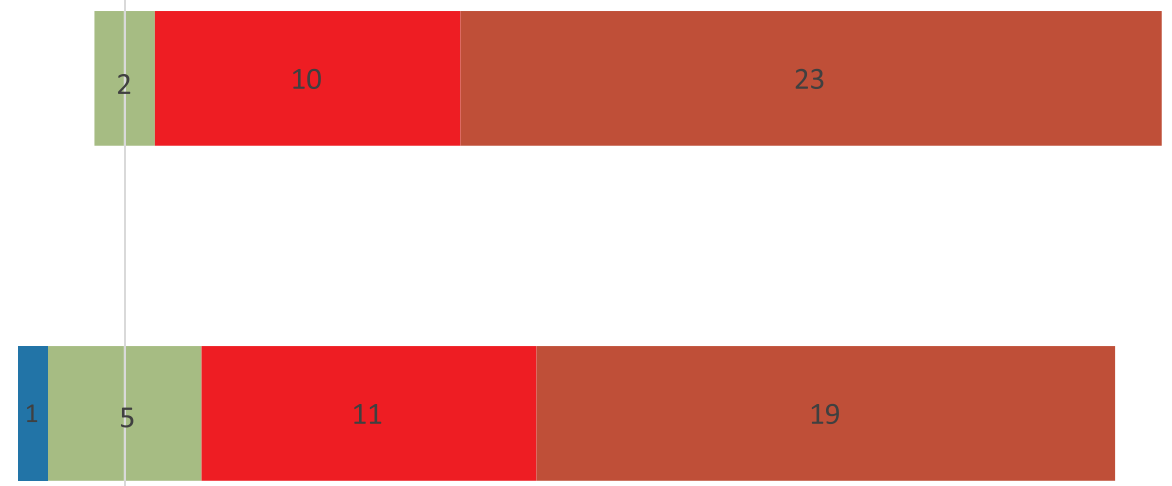

The clinician understood what was on my mind
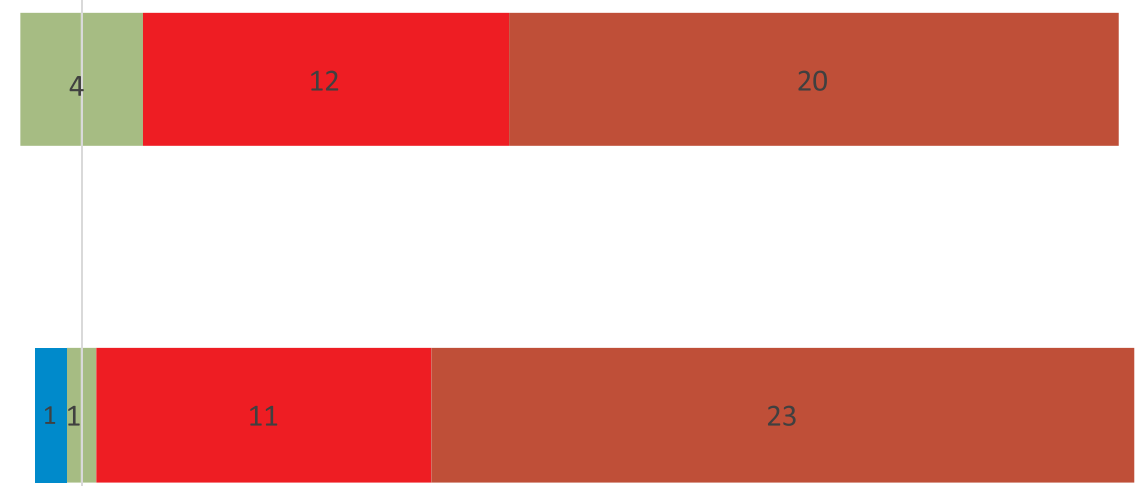

I felt I was taken

care of

Agree Completely agree $\quad$ So-so $\quad$ Disagree $\quad$ Disagree Completely

Figure 2 Results of Patient Experience Questionnaire questions 5 to 8. Response collected on a 5-point Likert Scale with each statement answered by one of the following "agree completely", "agree", "so-so", "disagree" or "disagree completely". Vertical line indicates most neutral answer. Numbers on boxes indicates number of responses in this category. Adapted from Steine S, Finset A, Laerum E. A new, brief questionnaire (PEQ) developed in primary care for measuring patients' experience of health interaction, emotion and consultation outcome. Fam Pract. 200I;18(4):410-4I7, by permission of Oxford University Press. ${ }^{13}$

measured by the Patient Experience Questionnaire (PEQ), was very similar whether the consultation was undertaken by an ophthalmologist or glaucoma practitioner.

\section{Discussion}

There is evidence from other areas of medicine that patient-clinician collaboration can be improved using interventions targeted at both patients and clinicians. We were keen to explore this in glaucoma but with very limited existing studies in this area, we undertook this pilot study. In addition to examining whether patient-clinician collaboration in glaucoma was an area that required improvement, we hoped this study would explore whether clinicians and patients would consent to being videotaped, whether our proposed methods of recording the collaborative nature of the consultations were workable, and whether the questionnaires produced useful data. As patient education is a potential intervention in this area we also wished to explore whether patients would be willing to consider receiving educational material or attending educational sessions.

This study explored the extent to which glaucoma consultations meet the principles of good collaborative clinicianpatient interaction and shared decision-making. We found the consultations to be largely "clinician-centred" with clinicians doing most of the talking and asking the majority of the questions. Glaucoma medications were discussed in $97 \%$ of consultations, and in $73 \%$, this included adherence and in $36 \%$ possible side effects. When a treatment change was recommended in only $53 \%$ were different options discussed, 
Patient Experience Questionnaire questions 9-12: Communication Barriers

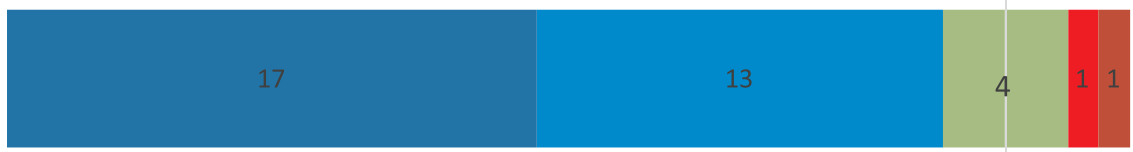

It was a bit difficult to connect with the clinician

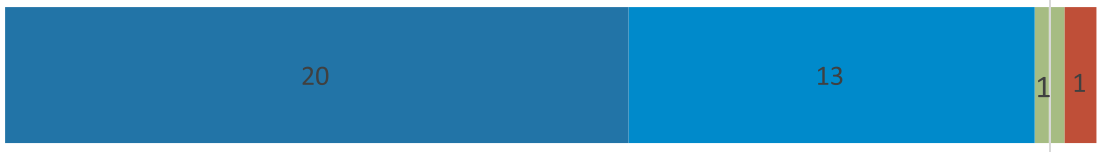

Too much time was spent on small talk

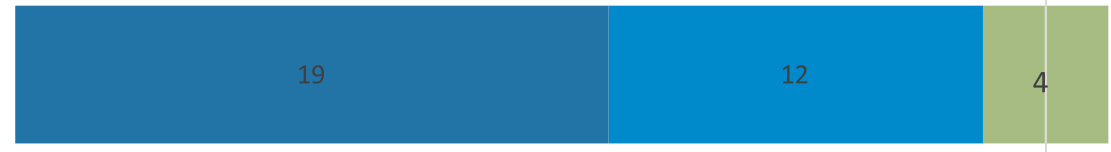

It was a bit difficult to ask questions

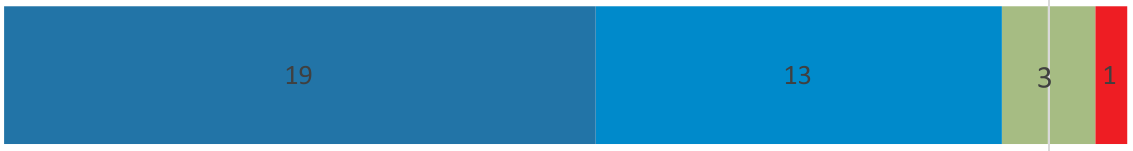

Important decisions were made over my head

Figure 3 Results of Patient Experience Questionnaire questions 9 to 12. Response collected on a 5-point Likert Scale with each statement answered by one of the following - "agree completely", "agree", "so-so", "disagree" or "disagree completely". Vertical line indicates most neutral answer. Numbers on boxes indicates number of responses in this category. Adapted from Steine S, Finset A, Laerum E. A new, brief questionnaire (PEQ) developed in primary care for measuring patients' experience of health interaction, emotion and consultation outcome. Fam Pract. 2001;18(4):410-417, by permission of Oxford University Press. ${ }^{13}$

and in only $32 \%$ the option of deciding against a change was mentioned. As the consultations drew to a close in only a minority of cases was the patient asked if they agreed with the timing of the next appointment or if they had any questions.

Glaucoma best practice guidelines from the American Academy of Ophthalmology, the Canadian Ophthalmological Society and the European Glaucoma Society all stress the importance of involving patients in decisions about their care. ${ }^{16-18}$ There is however a limited evidence base in ophthalmology on clinician-patient communication and collaborative decision-making. Two previous studies have reported that poor communication between glaucoma patients and their clinicians is associated with reduced adherence and another found that patients who reported being less likely to ask their eye doctor questions during visits also reported being less adherent to their glaucoma medication regimens. ${ }^{19-21}$ Another study showed the importance of patients' active involvement in their own care, with better self-management associated with higher vision-related quality of life scores. ${ }^{22}$

These studies, however, relied on self-report and we were only able to identify two previous instances of projects where ophthalmology consultations were videotaped in order to examine clinician-patient collaboration. Both of these involved glaucoma consultations.

The largest of these was undertaken by Sleath et al who videotaped the consultations of 279 patients and produced a number of reports on several aspects of 
Patient Experience Questionnaire questions 13-14: Experience with the auxillary staff

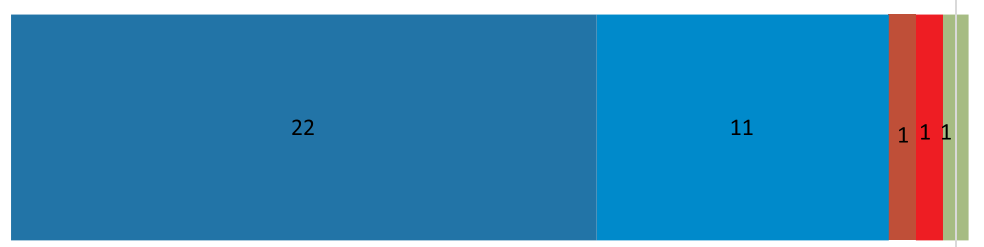

I sensed that other patients could listen in when I was talking to the staff

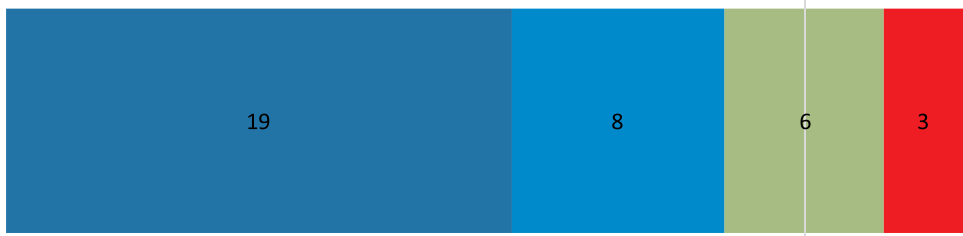

I felt like one of the crowd

agree Completely Agree $\quad$ So-so Disagree Disagree Completely

Figure 4 Results of Patient Experience Questionnaire questions 13 to 14. Response collected on a 5-point Likert Scale with each statement answered by one of the following - "agree completely", "agree", "so-so", “disagree” or "disagree completely”. Vertical line indicates most neutral answer. Numbers on boxes indicates number of responses in this category. Adapted from Steine S, Finset A, Laerum E. A new, brief questionnaire (PEQ) developed in primary care for measuring patients' experience of health interaction, emotion and consultation outcome. Fam Pract. 2001;18(4):410-417, by permission of Oxford University Press. ${ }^{13}$

clinician-patient communication. ${ }^{9,23-25}$ In one report they examined whether specific aspects of clinicianpatient interaction were associated with treatment adherence in the 60 days after the consultation. They found that provider information on how to instil drops was associated with improved adherence, but this information was only given in $14 \%$ of visits. They found no significant association between adherence and the physician educating the patient during the consultation about glaucoma, purpose of the medication, side effects or adherence strategies. Unlike the previous self-report study they did not find any link between adherence and whether patients asked questions during their consultations.

Fifty-one of the patients in Sleath et al's cohort were commenced on glaucoma treatment for the first time during the videotaped consultations and they concluded that clinicians did not use collaborative goal setting or take into account the individuals' views on glaucoma and its treatment. $^{9}$ In only 19 of the $51(37 \%)$ were patients given a treatment choice, and 13 of this 19 involved one clinician. Furthermore, of the 15 physicians who started patients on glaucoma treatment during this study, only 5 $(33 \%)$ gave treatment choices. Our study differed in that none of our participants were newly diagnosed, but similarly when a treatment change was recommended different options were only discussed in $53 \%$ of cases, and in $32 \%$ this included the option of the patient deciding on no change to treatment.

A study by Friedman et al videotaped 23 ophthalmologists undertaking 50 glaucoma consultations. ${ }^{10}$ The results were similar to this study, with clinicians speaking more than $70 \%$ of words and asking two-thirds of questions. Asking the patient towards the end of the consultation whether they have any questions appears to be a straightforward way of involving the patient more in the consultation and drawing out any uncertainties they have about the outcome of the consultation. This, however, 


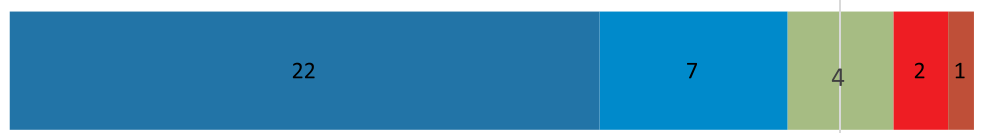

I feel happy with how involved I am in decisions about my care

I feel I would like to be more involved in decisions about my care
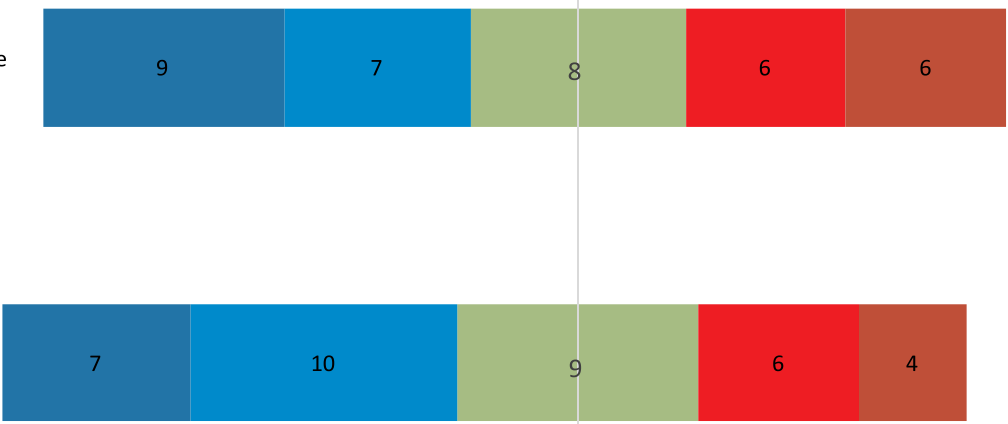

I would like to receive written information on how to be more involved in decisions about my care

I would consider attending an information session on how to be more involved in decisions about my care

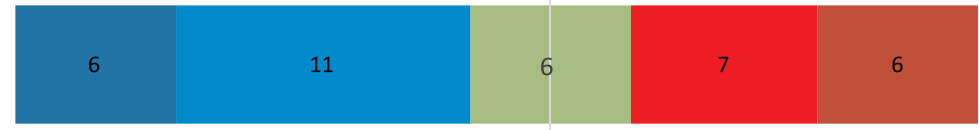

agree Completely agree So-so $\square$ Disagree $\square$ Disagree Completely

Figure 5 Results of glaucoma-specific questionnaire. Response collected on a 5-point Likert Scale with each statement answered by one of the following - "agree completely", "agree", "so-so", "disagree" or "disagree completely". Vertical line indicates most neutral answer. Numbers on boxes indicates number of responses in this category.

only happened in $18 \%$ of consultations in Friedman's study and $35 \%$ of the cases in our study.

The results of this study combined with Friedman and Sleaths' work suggest there is the potential for improvement in clinician-patient collaboration during glaucoma consultations. Although we were unable to find any similar studies in other areas of ophthalmology, there is a wealth of evidence from many areas of medicine that clinician-patient communication and collaboration are sub-optimal. ${ }^{5,7,12,26,27}$ This is despite good evidence of the benefits of good doctor-patient communication and collaborative decision-making. ${ }^{7,26-28}$ These benefits include increased adherence and in the Glaucoma Adherence and Persistence Study patients who had a more passive doctor-patient relationship were less well informed about their glaucoma and were less adherent to treatment. ${ }^{29}$ With adherence a major problem in glaucoma it may be that improving clinicians' communication skills would improve adherence. ${ }^{30,31}$ In the follow-up paper to the
Friedman study, the authors demonstrated that training ophthalmologists to improve their collaborative consultation skills and engagement in shared decision-making improved their communication skills and ability to detect nonadherence. ${ }^{11}$ In addition, there is evidence that patient education combined with personalised interventions improved adherence in glaucoma. ${ }^{32}$

The second aim of our study was to collect the patients' perspective of the videotaped consultations and explore their willingness to be more involved in decisions about their care. We found an overall positive opinion of the consultations, with patients indicating they felt the consultation would have a positive outcome and communication was good with no significant barriers. Their emotions immediately after the visit were also positive. These results fit with those of Friedman, who found that $96 \%$ of participants reported being "satisfied" or "very satisfied" with communication in the consultation. 
In the current study, the majority of patients were happy with how involved they are in decisions about their care. Despite this, many said they would like to be more involved and would welcome receiving written information or attending an information session in order to help them become more involved in these decisions.

That some patients are keen to be more involved in decisions about their care is consistent with findings from a survey involving cataract patients and a thematic analysis of calls to a UK glaucoma patient support helpline. ${ }^{33,34}$

Some of the findings in our study appear contradictory. On the one hand, patients appear largely satisfied with communication during their consultations and how involved they are in decisions about their care. On the other hand, the extent of clinician-patient collaboration which occurred during this study was limited and many patients wished to be more involved. These contradictions are consistent with previous studies outside ophthalmology, and may reflect the difficulty in measuring all aspects of clinician-patient interactions. ${ }^{35}$ An additional factor may be as highlighted by Friedman et al who concluded that although doctors and patients saw the benefits of greater collaboration, they were unable to move away from the traditional patient-doctor communication style. ${ }^{10}$ What is of little doubt is the importance patients put on clinicians' communication skills, using their "bedside manner" to judge their general competence. ${ }^{23}$ A US survey of over 4000 glaucoma patients revealed the most common reason for changing ophthalmologists was poor communication. ${ }^{36}$ That good clinician-patient interaction and increased patient participation in decisions about their care are good for both patients and clinicians is also clear. $^{2-8,26,28}$

Although the studies by Sleath and Friedman examined similar outcomes to our study there were significant differences in study populations. Both of these studies were USbased and involved only ophthalmologists. Our study was undertaken in the UK and the clinicians were a mixture of medically trained ophthalmologists and glaucoma practitioners with a range of primary qualifications such as nursing, optometry and orthoptics. This is typical in glaucoma care in the UK, where around $90 \%$ of glaucoma services include both medical and non-medical glaucoma practitioners for clinical assessment of glaucoma. ${ }^{37,38}$ Several studies have compared the examination and diagnostic skills of ophthalmologists with non-medical glaucoma practitioners, but to the best of our knowledge, no studies have compared communication and consultation skills between the two groups. ${ }^{39}$ Although we found that the degree of clinician-patient collaboration and the patient perception of the consultations to be very similar between the two groups the numbers of consultations do seem too small to come to any definitive conclusion, and this may be an area that would benefit from further research.

This study has several limitations. The sample size is relatively small due to the practicality and expense of recording and reviewing the consultations. A future study with larger numbers of clinicians and patients would allow exploration of whether characteristics of the participants such as years since qualification, years since diagnosis or severity of glaucoma affects the degree of collaboration during consultations. Although the study was designed to be as "real-life" as possible it may be that being recorded for a study looking at communication influenced the behaviour of both clinicians and patients. We do know, however, that patients and staff seem to adapt well to videotaping. ${ }^{40,41}$ In addition, some clinicians and patients may find recording of consultations intimidating, and it is possible that those who are more confident communicators were more likely to consent to take part in this study, and this may be a particular issue for patients with communication difficulties and where English is not their first language. Only $45 \%$ of those invited to take part in the study agreed and $75 \%$ of the patients who declined to participate declined to give a reason. In future studies in this area thought should be given on how to improve participation amongst patients with communication and language difficulties and also a more robust method of recording the reasons why some people decline to participate in the study. Finally, the degree of agreement between the two observers who assessed the videotaped consultations varied from moderate to substantial depending on the parameter scored. Although there is always a degree of subjectivity when observing human interactions, a more rigid predefined scoring system may limit this, and we would consider this for any future studies in this area.

In summary in this pilot study, we found that glaucoma consultations remain "clinician-centred". These findings are consistent with other studies in ophthalmology and medicine as a whole and, in view of the evidence of the benefits of good clinician-patient collaboration, suggests further studies to examine interventions to improve clinician-patient collaboration are likely to be of benefit to glaucoma patients. Which interventions are likely to be of most effective is unclear but possibilities include written material or training sessions aimed at educating 
clinicians on the benefits of a more collaborative approach, perhaps combined with some practical skills in achieving this. In addition, many patients in this study would like to be more involved in decisions about their care and would welcome support in achieving this, such as the provision of written guidance or information sessions, and how best to approach this is another area which is worthy of further investigation.

\section{Acknowledgment}

This study was funded by the West of England Eye Infirmary Charitable Trust Fund. The funding organization had no role in the design or conduct of this research.

\section{Disclosure}

None of the authors have any conflicts of interest to declare in relation to the work presented in this paper.

\section{References}

1. Kaba R, Sooriakumaran P. The evolution of the doctor-patient relationship. Int J Surg. 2007;5:57-65. doi:10.1016/j.ijsu.2006.01.005

2. O'Grady L, Jadad A. Shifting from shared to collaborative decision making: a change in thinking and doing. J Participat Med. 2010;2: e13.

3. NHS England. Shared decision making summary guide; 2019. Available from: https://www.england.nhs.uk/wp-content/uploads/ 2019/01/shared-decision-making-summary-guide-v1.pdf. Accessed February 07, 2020.

4. O'Connor A, Bennett C, Stacey D, et al. Decision aids for people facing health treatment or screening decisions. Cochrane Database Syst Rev. 2009;3:CD001431.

5. Elwyn G, Laitner S, Coulter A, Walker E, Watson P, Thomson R. Implementing shared decision making in the NHS. BMJ. 2010;341: c5146. doi:10.1136/bmj.c5146

6. Gravel K, Legare F, Graham ID. Barriers and facilitators to implementing shared decision-making in clinical practice: a systematic review of health professionals' perceptions. Implement Sci. 2006;1:16. doi:10.1186/1748-5908-1-16

7. Maskrey N. Shared decision making: why the slow progress? An essay by Neal Maskrey. BMJ. 2019;367:16762. doi:10.1136/bmj. 16762

8. O'Connor AM, Légaré F, Stacey D. Risk communication in practice: the contribution of decision aids. BMJ. 2003;327:736-740. doi:10.1136/bmj.327.7417.736

9. Sleath B, Slota C, Blalock SJ, et al. Provider use of collaborative goal setting with glaucoma patients. Optom Vis Sci. 2014;91:549-555. doi:10.1097/OPX.0000000000000244

10. Friedman DS, Hahn SR, Quigley HA, et al. Doctor-patient communication in glaucoma care. Analysis of videotaped encounters in community-based office practice. Ophthalmology. 2009;116:2277-2285. doi:10.1016/j.ophtha.2009.04.052

11. Hahn SR, Friedman DS, Quigley HA, et al. Effect of patient-centered communication training on discussion and detection of nonadherence in glaucoma. Ophthalmology. 2010;117:1339-1347. doi:10.1016/j. ophtha.2009.11.026

12. Légaré F, Stacey D, Turcotte $S$, et al. Interventions for improving the adoption of shared decision making by healthcare professionals. Cochrane Database Syst Rev. 2014;9:CD006732.
13. Steine S, Finset A, Laerum E. A new, brief questionnaire (PEQ) developed in primary care for measuring patients' experience of health interaction, emotion and consultation outcome. Fam Pract. 2001;18(4):410-417. doi:10.1093/fampra/18.4.410

14. NHS England. Measuring shared decision making; 2012. Available from: https://www.england.nhs.uk/wp-content/uploads/2013/08/ 7sdm-report.pdf. Accessed February 05, 2020.

15. Landis JR, Koch GG. The measurement of observer agreement for categorical data. Biometrics. 1977;33:159-174. doi:10.2307/2529310

16. Prum BE, Rosenberg LF, Gedde SJ, et al. Primary open-angle glaucoma preferred practice pattern guideline. Ophthalmology. 2016;123:41. doi:10.1016/j.ophtha.2015.10.053

17. Rafuse PE, Buys YM, Damji KF, et al. Canadian Ophthalmological Society evidence based clinical practical guidelines for the management of glaucoma in the adult eye. Can J Ophthalmol. 2009;44:S7-93.

18. European Glaucoma Society Terminology and Guidelines for Glaucoma, 4th Edition - Chapter 3: treatment principles and options. Supported by the EGS Foundation. $B r \quad J$ Ophthalmol. 2017;101:130-195.

19. Taylor SA, Galbraith SM, Mills RP. Causes of noncompliance with drug regimens in glaucoma patients: a qualitative study. $J$ Ocul Pharmacol Ther. 2002;18:401-409. doi:10.1089/ 10807680260362687

20. Tsai JC, McClure CA, Ramos SE, et al. Compliance barriers in glaucoma: a systematic classification. $J$ Glaucoma. 2003;12:393-398. doi:10.1097/00061198-200310000-00001

21. Stryker JE, Beck AD, Primo SA, et al. An exploratory study of factors influencing glaucoma treatment adherence. $J$ Glaucoma. 2010;19:66-72. doi:10.1097/IJG.0b013e31819c4679

22. Wu P, Xi S, Xia H, Lu H, Guo W. Survey on vision-related quality of life and self-management among patients with glaucoma. J Glaucoma. 2014;23:75-80. doi:10.1097/IJG.0b013e318265bbf3

23. Sleath B, Blalock SJ, Carpenter DM, et al. Provider education about glaucoma and glaucoma medications during videotaped medical visits. J Ophthalmol. 2014;2014:238939. doi:10.1155/2014/238939

24. Sleath B, Blalock SJ, Carpenter DM, et al. Ophthalmologist-patient communication, self-efficacy, and glaucoma medication adherence. Ophthalmology. 2015;122(4):748-754. doi:10.1016/j.ophtha.2014.11.001

25. Carpenter DM, Tudor GE, Sayner R, et al. Exploring the influence of patient-provider communication on intraocular pressure in glaucoma patients. Patient Educ Couns. 2015;98:1558-1597. doi:10.1016/j. pec.2015.07.001

26. Ha JF, Longnecker N. Doctor-patient communication: a review. Ochsner J. 2010;10:38-43.

27. Lipton RB, Hahn SR, Cady RK, et al. In-office discussion of migraine: results from the American Migraine Communication Study. J Gen Intern Med. 2008;23:1145-1151. doi:10.1007/s11606008-0591-3

28. Stiggelbout AM, Van der Weijden T, De Wit MP, et al. Shared decision making: really putting patients at the centre of healthcare. BMJ. 2012;344:e256. doi:10.1136/bmj.e256

29. Friedman DS, Hahn SR, Gelb L, et al. Doctor-patient communication, health-related beliefs, and adherence in glaucoma: results from the Glaucoma Adherence and Persistence Study. Ophthalmology. 2008;115:1320-1327. doi:10.1016/j.ophtha.2007.11.023

30. Olthoff CM, Schouten JS, van de Borne BW, Webers CA. Noncompliance with ocular hypotensive treatment in patients with glaucoma or ocular hypertension an evidence based review. Ophthalmology. 2005;112(6):953-961. doi:10.1016/j.ophtha.200 4.12.035

31. Lu VH, Goldberg I, Lu CY. Use of glaucoma medications: state of the science and directions for observational research. $\mathrm{Am}$ J Ophthalmol. 2010;550(4):568-574.

32. Waterman H, Evans JR, Gray TA, Henson D, Harper R. Interventions for improving adherence to ocular hypotensive therapy. Cochrane Database Syst Rev. 2013;4:CD006132. 
33. Zheng YF, Huang WY, Xiao BX, et al. Preferences for participation in shared decision-making among cataract patients in urban southern China: a cross-sectional study. Lancet. 2016;388(1):S56. doi:10.1016/ S0140-6736(16)31983-3

34. Osborn K, Bradley J, Knox E, et al. What matters to patients? A thematic analysis of patient information and support needs. Eye. 2020;34:103-115. doi:10.1038/s41433-019-0644-3

35. Wunderlich T, Cooper G, Divine G, et al. Inconsistencies in patient perceptions and observer ratings of shared decision making: the case of colorectal cancer screening. Patient Educ Couns. 2010;80 (3):358-363. doi:10.1016/j.pec.2010.06.034

36. Herndon LW, Brunner TM, Neff Rollins J. The glaucoma research foundation patient survey: patient understanding of glaucoma and its treatment. Am J Ophthalmol. 2006;141:S22-S27. doi:10.1016/j. ajo.2005.06.028

37. Royal College of Ophthalmologists. The way forward: glaucoma; 2017. Available from: https://www.rcophth.ac.uk/wp-content /uploads/2015/10/RCOphth-The-Way-Forward-Glaucoma-300117. pdf. Accessed February 01, 2020.
38. Harper RA, Gunn PJ, Spry PG, Fenerty CH, Lawrenson JG. Care pathways for glaucoma detection and monitoring in the UK. Eye. 2020;34:89-102. doi:10.1038/s41433-019-0667-9

39. National Institute for Health and Clinical Excellence. Glaucoma: diagnosis and management; 2017. Available from: https://www.nice. org.uk/guidance/ng81/evidence/full-guideline-pdf-4660991389. Accessed May 01, 2020.

40. Themessl-Huber M, Humphris G, Dowell J, et al. Audiovisual recording of patient-GP consultations for research purposes: a literature review on recruiting rates and strategies. Patient Educ Couns. 2008;71:157-168. doi:10.1016/j.pec.2008.01.015

41. Penner LA, Orom H, Albrecht TL, et al. Camera-related behaviors during video recorded medical interactions. J Nonverbal Behav. 2007;31:99-117. doi:10.1007/s10919-007-0024-8
Clinical Ophthalmology

\section{Publish your work in this journal}

Clinical Ophthalmology is an international, peer-reviewed journal covering all subspecialties within ophthalmology. Key topics include: Optometry; Visual science; Pharmacology and drug therapy in eye diseases; Basic Sciences; Primary and Secondary eye care; Patient Safety and Quality of Care Improvements. This journal is indexed on PubMed

\section{Dovepress}

Central and CAS, and is the official journal of The Society of Clinical Ophthalmology (SCO). The manuscript management system is completely online and includes a very quick and fair peer-review system, which is all easy to use. Visit http://www.dovepress.com/ testimonials.php to read real quotes from published authors. 